Annales Geophysicae (2001) 19: 1655-1668 C) European Geophysical Society 2001

\title{
Cluster boundary layer measurements and optical observations at magnetically conjugate sites
}

\author{
J. Moen ${ }^{1,2}$, J. A. Holtet ${ }^{1}$, A. Pedersen ${ }^{1}$, B. Lybekk ${ }^{1}$, K. Svenes ${ }^{3}$, K. Oksavik ${ }^{4}$, W. F. Denig ${ }^{5}$, E. Lucek ${ }^{6}$, F. Søraas ${ }^{4}$, and \\ M. André 7 \\ ${ }^{1}$ Department of Physics, University of Oslo, P. O. Box 1048 Blindern, N-0316 Oslo, Norway \\ ${ }^{2}$ Also at Arctic Geophysics, University Courses on Svalbard, N-9170 Longyearbyen, Norway \\ ${ }^{3}$ Norwegian Defence Research Establishment, Division for Electronics, P. O. Box 25, N-2007 Kjeller, Norway \\ ${ }^{4}$ Department of Physics, University of Bergen, N-5007 Bergen, Norway \\ ${ }^{5}$ Air Force Research Laboratory, Space Vehicles Directorate, Hanscom AFB, MA 01731-3010, USA \\ ${ }^{6}$ Space and Atmospheric Physics Group, Blackett Laboratory, Imperial College, London, SW7 2BW, UK \\ ${ }^{7}$ Swedish Institute of Space Physics, Uppsala Division P. O. Box 537, SE-751 21 Uppsala, Sweden
}

Received: 21 March 2001 - Revised: 15 June 2001 - Accepted: 19 June 2001

\begin{abstract}
The Cluster spacecraft experienced several boundary layer encounters when flying outbound from the magnetosphere to the magnetosheath in the dusk sector on 14 January 2001. The dayside boundary layer was populated by magnetosheath electrons, but not with quite as high densities as in the magnetosheath itself. The Cluster ground track was calculated using the Tsyganenko-96 model which appears to be a strong tool for combining high-altitude satellite and ground observations, given that the solar wind conditions are known. This paper focuses on identifying auroral responses corresponding to boundary layer dynamics observed by Cluster. The first boundary layer encounter studied was a brief visit into a closed LLBL, most likely due to a boundary wave that travelled tailward over the spacecraft. A corresponding equatorward and eastward movement was seen in the post-noon aurora between Greenland and Svalbard. The second boundary encounter was in a high-latitude cusp, and occurred as a consequence of a transient reconfiguration of the cusp. The cusp expanded duskward over the spacecraft into the late post-noon sector. NOAA-12 probed the 16:30 MLT sector of this auroral activity, and measured a $1.4 \mathrm{keV}$ electron beam located poleward of the $30 \mathrm{keV}$ electron-trapping boundary. A sequence of three moving auroral forms emanating from this active region are likely candidates for flux transfer events. The auroral signatures are discussed in relation to earlier observations, and appear to be an example of accelerated electrons/discrete post-noon aurora on open magnetic field lines.
\end{abstract}

Key words. Ionosphere (particle precipitation) Magnetospheric physics (auroral phenomena; magnetopause, cusp

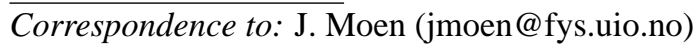

and boundary layers)

\section{Introduction}

Data from low-altitude polar orbiting satellites, combined with optical observations from the ground, have been used intensively for more than a decade as an indirect approach for determining magnetospheric boundary layer sources of auroral phenomena. Newell and Meng $(1988,1992)$ subdivided the "soft zone" dayside precipitation region, located poleward of the central plasma sheet (CPS), into four different regions: the dayside extension of the boundary plasma sheet (BPS), the low-latitude boundary layer (LLBL), cusp proper, and mantle. They established an automated identification scheme to discriminate among the four precipitation regions. Newell and Meng (1992) presented a probability map for observing the various boundary layers, where the cusp proper spans $\sim 3$ hours centred on local noon $(\sim 10: 30$ 13:30 MLT). In the ionosphere, the LLBL borders on the equatorward side of the cusp near noon, but extends further pre- and post-noon than the cusp ( 09:00-15:00 MLT). The plasma mantle borders on the poleward side of the cusp and the LLBL. The BPS borders on the dawn and dusk end of the LLBL. The key distinction between the LLBL and the cusp is the presence of energetic magnetospheric particles in the LLBL. The BPS is characterised by more spatially and spectrally structured electron precipitation than the CPS. The BPS also contains a dense component of accelerated magnetosheath-like ions.

Sandholt et al. (1998) subdivided dayside auroral activities into seven types, and tentatively associated them with the statistical precipitation map described above. Type 1 
occurs in the midday sector (09:00-15:00 MLT) for southward IMF, and is dominated by the $630.0 \mathrm{~nm}$ emission. It includes rayed bands and quasi-periodic sequences of poleward moving auroral forms (PMAFs). Type 1 aurora comprise of open LLBL, cusp, and mantle (Sandholt et al., 1993; Moen et al., 1998), and the moving auroral forms are believed to be footprints of flux transfer events (FTEs). Type 2 is dominated by the $630.0 \mathrm{~nm}$ emission, but is located at much higher latitudes than type 1 . Type 2 is stimulated by magnetosheath electrons injected by lobe reconnection for northward IMF (Øieroset et al., 1997). Type 3 is a diffuse glow of $557.7 \mathrm{~nm}$, and is located equatorward of type 1 with an emission gap in between. It is attributed to pitch-angle scattered energetic electrons from the CPS (Lorentzen et al., 1996; Moen et al., 1998). Types 4 and 6 are discrete forms in the pre-noon sector (06:00-09:00 MLT) for IMF $B_{Z}$ north and south, respectively. They are strong in both the 557.7 and $630.0 \mathrm{~nm}$, and attributed to a BPS origin on sunward convection (Ober et al., 2000; Farrugia et al., 2000; Lorentzen and Moen, 2000). Types 5 (IMF $B_{Z}$ north) and 7 (IMF $B_{Z}$ north) are discrete forms in the dusk sector (15:00-18:00 MLT) containing strong red and green line emissions, also attributed to BPS on a sunward flow. It must be noted that the division of DMSP precipitation signatures into BPS, LLBL, cusp and mantle regions are based strictly on quantitative criteria and as such, are just names referring to the classification scheme invented by Newell and Meng (1988). However, it does not seem likely that what is identified as BPS in the ionosphere always maps to the boundary of the plasma sheet in the magnetosphere. Model simulations have shown that open LLBL, cusp, and mantle are at different stages of the evolution of a newly-reconnected flux convecting away from the merging site. It is now accepted that the LLBL may be entirely on open field lines (Lockwood and Moen, 1996; Moen et al., 1996; Lockwood et al., 1998). "BPS precipitation", differentiated from low-altitude LLBL signatures by spatially structured field-aligned acceleration and discrete arcs, is believed to map to the boundary of the plasma sheet and hence, is located on closed field lines. However, the energy-dispersed ion signature, interpreted as a reconnection signature, sometimes begins in the "BPS" (Lockwood et al., 1998). Milan et al. (2000) presented UVI images and HF radar observations suggesting that PMAFs can be seven hours of MLT in length and extend as far as 19:00 MLT. Hence, the "BPS" class of auroral precipitation may not always have a physical relationship to the "boundary of the plasma sheet", which is per definition closed.

In this paper, we present two auroral events in the 15:0017:00 MLT sector west of Svalbard, which appear magnetically conjugate with high-altitude Cluster observations. Conjunction was obtained when Cluster encountered the boundary layer plasma in the dusk sector on 14 January 2001 . We will demonstrate the use of the Tsyganenko-96 model (Tsyganenko, 1995) to identify magnetic conjugacy between the Cluster spacecraft and the auroral ionosphere, noting that conjugacy is sensitive to solar wind conditions and has associated uncertainties. Available Cluster data for this study are electron particle data from the plasma electron and current experiment (PEACE), spacecraft potential, electric field measurements from the field and wave experiment (EFW), and magnetic field measurements from the fluxgate magnetometers (FGM).

\section{Instrumentation}

Each cluster spacecraft carries an electric field and wave experiment (EFW). This experiment measures the potential difference between two perpendicular axes of double probes; the spherical probes are mounted at the tips of four radial booms $44 \mathrm{~m}$ in length. The electric field probes are electronically controlled to be 0.5 to $1.0 \mathrm{~V}$ positive, relative to the ambient plasma and can serve as a reference for the spacecraft potential which, in turn, can be calibrated to provide information about electron density. More details are given in Gustafsson et al. (2001, this issue). Initial calculations in the solar wind, when compared with measured ion drift speeds, have demonstrated accuracies to a fraction of one $\mathrm{mV} / \mathrm{m}$. The electric field experiment provides information about the electric field components $E_{X}(\mathrm{GSE})$ and $E_{Y}(\mathrm{GSE})$ in the spin plane.

Each Cluster spacecraft carries two triaxial fluxgate magnetometers (FGM) to measure the magnetic field, one located at the end of a $5.2 \mathrm{~m}$ radial boom of the spacecraft and the other $1.5 \mathrm{~m}$ inward from the end of the boom. Either sensor can be designated as the primary sensor. At nominal mode, the primary sensor provides 15.519 magnetic field vectors per second. The data presented in this paper has the spin rate resolution of $4 \mathrm{~s}$ (see Balogh et al. (1997) for a detailed description of the Cluster magnetic field investigation).

The PEACE (Plasma Electron and Current Experiment) instrument is a dual sensor system designed to measure the three-dimensional velocity distribution of electrons in the energy range from $0.6 \mathrm{eV}$ to $27 \mathrm{keV}$, and to detect electrons arriving from all pitch-angles. The instrument consists of a data processing unit and two sensors. The sensors are hemispherical electrostatic energy analysers with position-sensitive micro-channel plate detectors. Each sensor is mounted on the spacecraft so as to observe a $180^{\circ}$ fieldof-view in the plane defined by the spacecraft spin axis and the radial direction in the spin plane. The two sensors, LEEA and HEEA (Low and High Energy Electron Analysers), are mounted on opposite sides of the spacecraft so that they have a combined instantaneous field-of-view of $360^{\circ}$. In normal operations, the sensors operate at a rate of 32 sweeps in each four-second satellite spin. LEEA covers the range up to about $1000 \mathrm{eV}$, and HEEA covers the range from about $40 \mathrm{eV}$ to about $27 \mathrm{keV}$. Technically, either sensor can cover the full energy range, although in certain environments, the difference in geometric factor means that one or the other sensor is preferred to cover particular energy ranges (the reader is referred to Johnstone et al. (1997) for a full description of the instrument). 


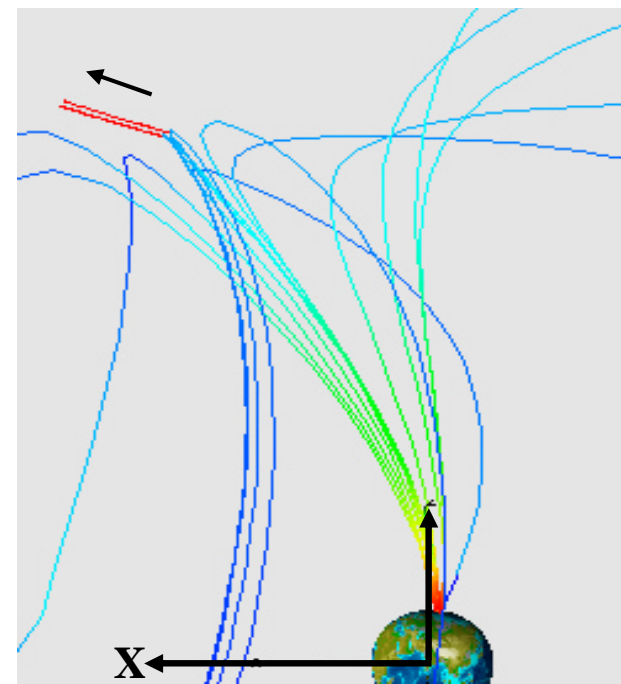

GSE XZ

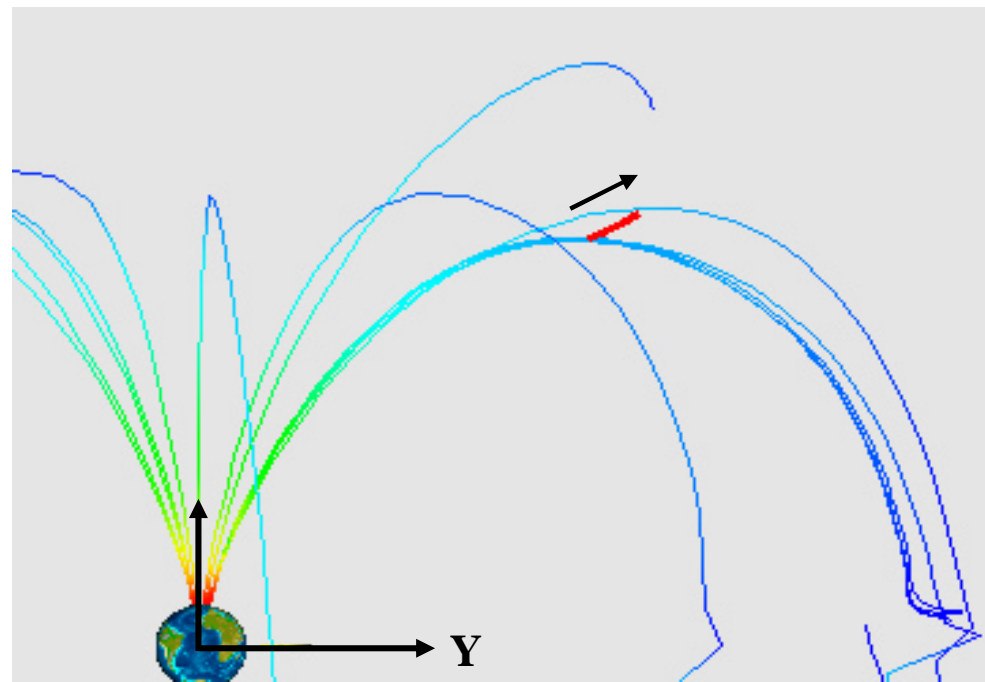

GSE YZ

Fig. 1. An illustration of the flight path (in red) of Cluster from 12:30 to 14:00 UT in a GSE $X-Z$ and $Y-Z$ plane. Cluster moved radially outward in the dusk sector for the actual time interval.

Essential information about auroral particle precipitation is provided by the low-altitude, sun-synchronous polar orbiting satellites DMSP-14 and NOAA-12, which both operate at about an $800 \mathrm{~km}$ altitude. The DMSP satellites are equipped with separate electron and ion ElectroStatic Analysers (ESAs) having fields-of-view along the local zenith. The ESAs measure the energy spectrum once per second of precipitating charged particles within the range from $32 \mathrm{eV}$ to $32 \mathrm{keV}$. They are also equipped with a thermal plasma drift meter (DM) measuring the horizontal and vertical cross-track velocity components of the ionospheric plasma. The NOAA satellites carry two complements of particle instruments, the Total Energy Detector (TED) and the Medium Energy Proton and Electron Detector (MEPED). TED measures electrons and ions between 0.3 and $20 \mathrm{keV}$, in two viewing directions, one toward zenith and the other $30^{\circ}$ to zenith. This instrument has been designed to obtain the energy flux moment, but also provides crude electron and ion energy spectra as well. MEPED consists of solid-state detector telescopes, one pointing toward zenith to view particles that precipitate into the ionosphere, the other at $90^{\circ}$ to zenith to view particles that will magnetically mirror above the atmosphere. The energy ranges for electrons are $>30 \mathrm{keV},>100 \mathrm{keV}$, $>300 \mathrm{keV}$, all with a $1000 \mathrm{keV}$ maximum energy, and for ions $30-80 \mathrm{keV}, 80-250 \mathrm{keV}, 250-800 \mathrm{keV}, 800-2500 \mathrm{keV}$ and $>2500 \mathrm{keV}$. MEPED provides information on energetic magnetospheric particle fluxes $(>30 \mathrm{keV})$ and helps locate the electron trapping boundary.

The auroral activity was surveyed by an all-sky imager (ASI) located at Ny-Ålesund $\left(78.9^{\circ} \mathrm{N}, 11.9^{\circ} \mathrm{E}, 76.07^{\circ}\right.$ CGMLAT). The Tsyganenko-96 magnetic field model (T96) is used to connect the Cluster in situ measurements to the ground-optical observations.

\section{Observations}

Figure 1 illustrates the location of Cluster above the northern hemisphere on 14 January 2001, viewed in a GSE $X Z$ plane in the left panel and in a GSE $Y Z$ plane on the right. The spacecraft 1, like the other three spacecraft (spacecraft 2 to spacecraft 4$)$ were at GSE position $(2.72,8.03,9.13) R_{E}$ at 12:30 UT. The red curve in each panel marks the orbital path travelled from 12:30 to 14:00 UT. Direction of movement is indicated by an arrow. The Cluster satellites moved outward from the magnetosphere towards the post-noon dayside magnetopause when collecting the data to be presented. The figure was made using the orbit visualization tool for Cluster (http://ovt.irfu.se) employing the T96 model for the magnetic field.

Figure 2 shows the interplanetary magnetic field observed by ACE in GSM coordinates from 11:00-14:00 UT. $B_{Z}$ was predominantly positive up to 13:30 UT, except for brief negative excursions at around 11:50 UT, 12:30 UT and 12:40 UT. $B_{X}$ varied between 0 and $-5 \mathrm{nT}$, and $B_{Y}$ from -4 to $4 \mathrm{nT}$. ACE measured a solar wind bulk speed of $\sim 380 \mathrm{~km} / \mathrm{s}$, corresponding to an advection time of about one hour between the position of ACE at $\sim 230 R_{E}$ upstream and the Earth's magnetopause. We are going to study two boundary layer encounters starting at 12:51 and 13:30 UT. The dot-dashed vertical lines indicate the corresponding IMF at the beginning of these two encounters (BL-E1 and BL-E2), assuming a 60 min signal propagation time between $\mathrm{ACE}$ and Cluster. The two full lines mark the time lag of $75 \mathrm{~min}$. Lockwood et al. (2001, this issue) applied a time shift of 75 min for the time interval between $\sim 08: 30$ and 12:00 UT, and found good correlation between IMF $B_{Z}$ and the $X$ component deflections observed by the Svalbard ground magnetometers. 


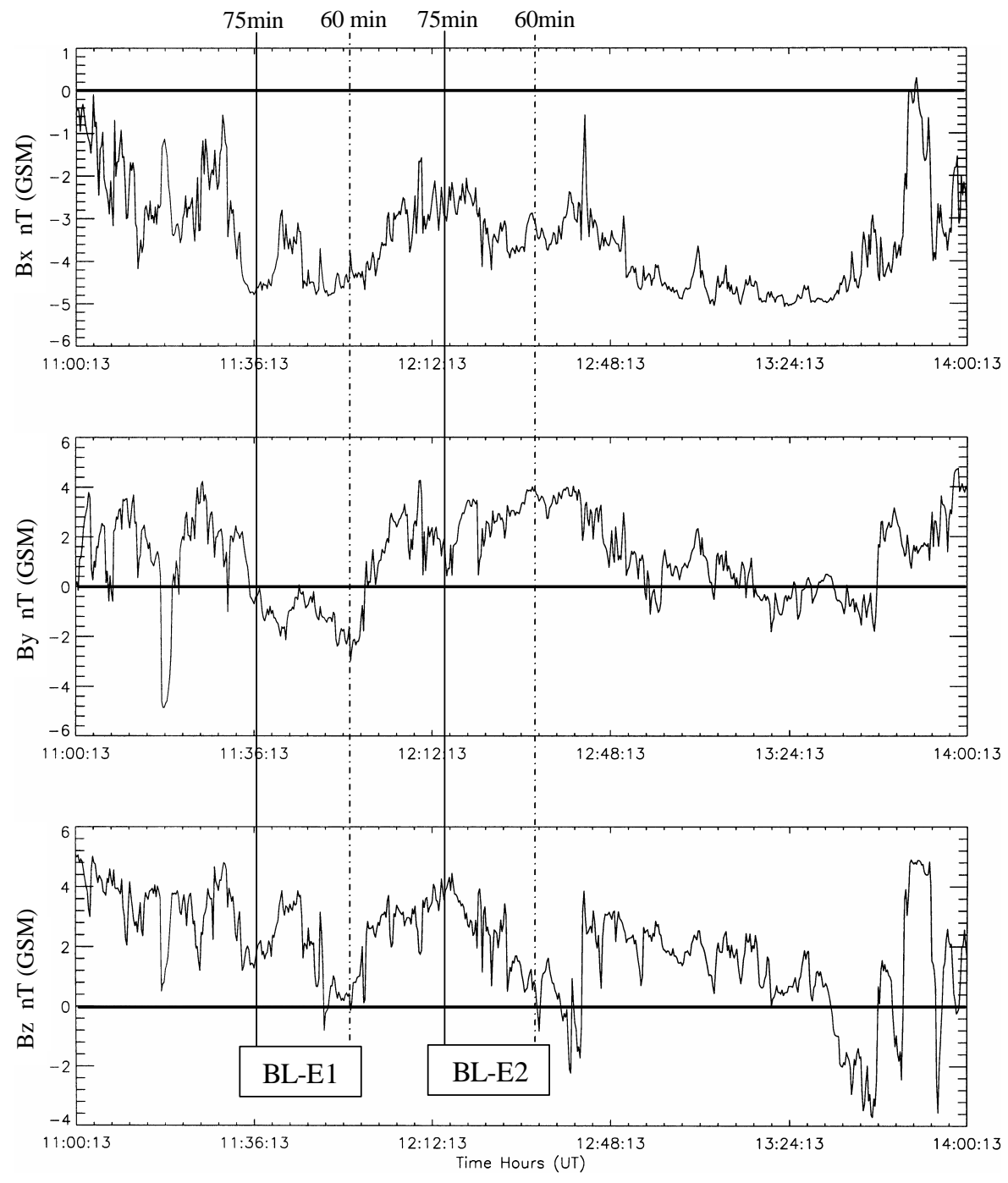

Fig. 2. The components $B_{X}, B_{Y}$, and $B_{Z}$ of the interplanetary magnetic field in GSM coordinates observed by ACE near the L1 point. The full and dotdashed vertical lines mark the IMF conditions for two boundary layer encounters by Cluster assuming a time shift of 75 and $60 \mathrm{~min}$.
Optgenoorth et al. (2001, this issue) report an excellent correlation between the IMF clock angle (in the GSE $Y-Z$ plane) observed by ACE and that observed by Cluster in the magnetosheath after about 15:00 UT, when the spacecraft had crossed the magnetopause. Their cross-correlation peaked for a time shift of $74 \mathrm{~min}$. Such a firm assessment of the time lag has not been established between 12:00 and 15:00 UT, and we will run the Tsyganenko model with both 60 and 75 min time lags of the IMF.

Figure 3 presents observations from the PEACE and EFW experiments on spacecraft 1 from 12:30 to 15:30 UT. The top panel shows a colour-coded electron spectrogram from PEACE, where accumulated counts (for LEEA) are plotted versus energy and time. At first glance, we see that the spacecraft alternated between two distinct plasma populations, i.e. high-density low energy electrons (30-200 eV), and lowdensity energetic electrons that can be glimpsed at the highest energy ranges. The absence of the low energy electrons at the beginning tells us that the spacecraft initially was inside the magnetopause, where the measurements are dominated by the energetic ( $E>1 \mathrm{keV}$ ) particles usually encountered on closed field lines. Between 12:52 and 15:15 UT, it had several encounters with a low energy electron population; the first one lasted $\sim 4$ min from 12:52 to 12:56 UT, and the most extensive one lasted $\sim 30 \mathrm{~min}$ from 13:27 to 13:57 UT. Notably, the high-energy component disappears at every excursion into the low energy electron regime. At 15:15 UT, the spacecraft had definitely reached the magnetosheath.

The second panel from the top in Fig. 3 shows the negative of the spacecraft potential with an electron density scale on the right side. This way of plotting the spacecraft potential means that increasing electron density is upwards. This parameter has periodic variations between $-20 \mathrm{~V}$ and $-25 \mathrm{~V}$ in the tenuous magnetospheric plasma. This periodic variation is caused by the short operation of the plasma resonance sounder, Whisper, on Cluster. The upper trace corresponds to the $N_{e}$ scale on the right side of this panel.

By comparing spacecraft potential with PEACE electron data, it is evident that spacecraft potential is a useful parameter for locating boundary layer crossings between low- and 

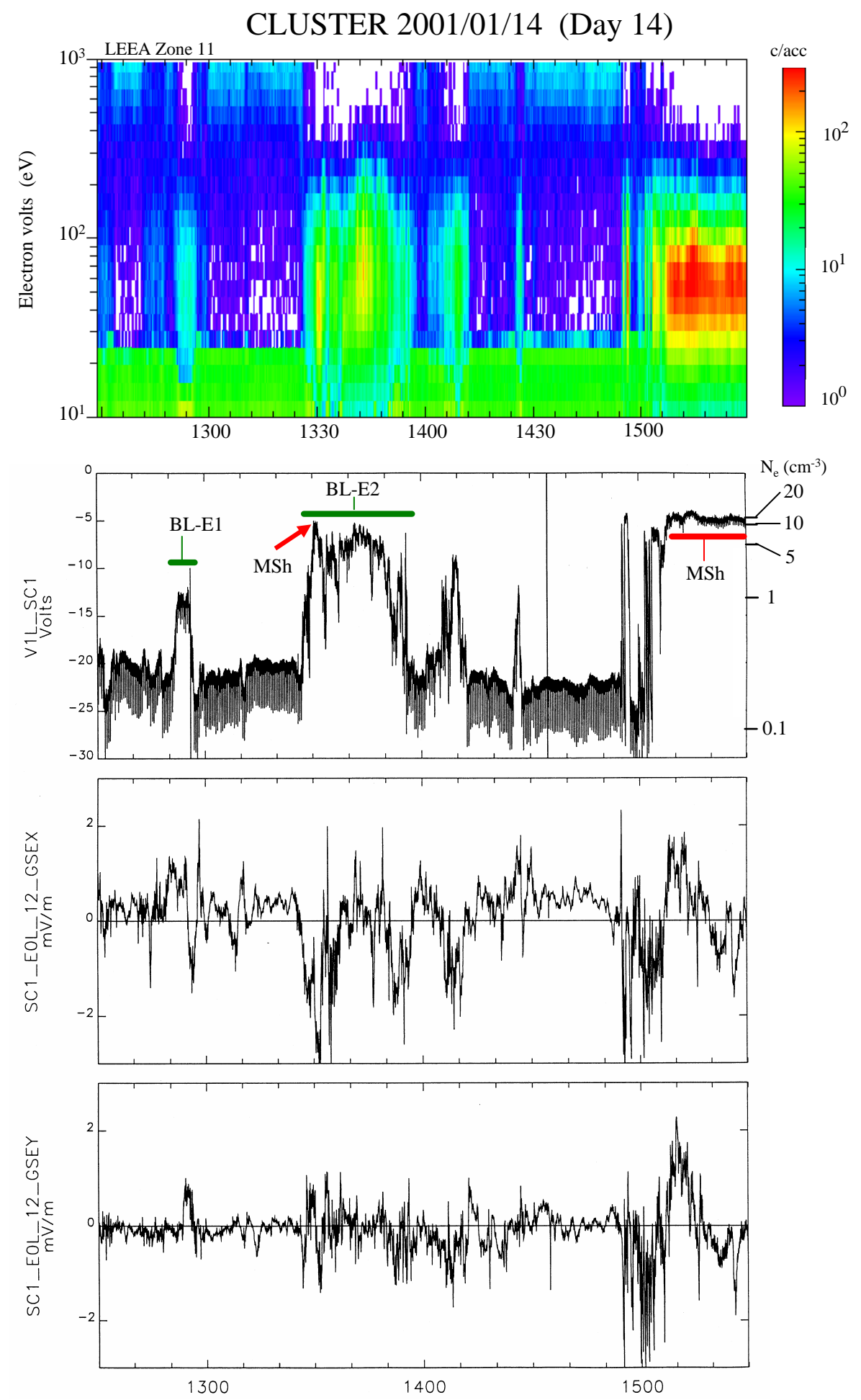

Fig. 3. The top panel shows the spectrogram obtained by PEACE at spacecraft 1 from 12:30-15:30 UT. The accumulated counts in each energy bin (for LEEA) have been plotted as a function of time (colour bar on right side). The second panel from the top represents the negative of the spacecraft potential for spacecraft 1 . The spacecraft potential has been calibrated against electron density, and the electron density scale is given on the right. The two bottom panels show the GSE $X$ and $Y$ components of the electric field versus time. high-density plasma populations. After 15:15 UT, when the satellite had entered the magnetosheath, the negative of the plasma potential reaches a quasi-steady level of $-5 \mathrm{~V}$. The two boundary layer excursions that will be linked to auroral activity enhancements west of Svalbard are annotated BLE1 and BL-E2, meaning boundary layer encounter 1 and 2. The density associated with BL-E1 is significantly lower than that for BL-E2, and the corresponding spacecraft potential is around $-14 \mathrm{~V}$ and $-7 \mathrm{~V}$, respectively. The electric field components $E_{X}(\mathrm{GSE})$ and $E_{Y}(\mathrm{GSE})$ are given in the lower two panels of Fig. 3. The electric field GSE $E_{X}$ and $E_{Y}$ components are directly measured on Cluster. The $X Y$-plane is identical to the spacecraft spin plane. When the magnetic field has a direction larger than approximately $10^{\circ}$ with the 


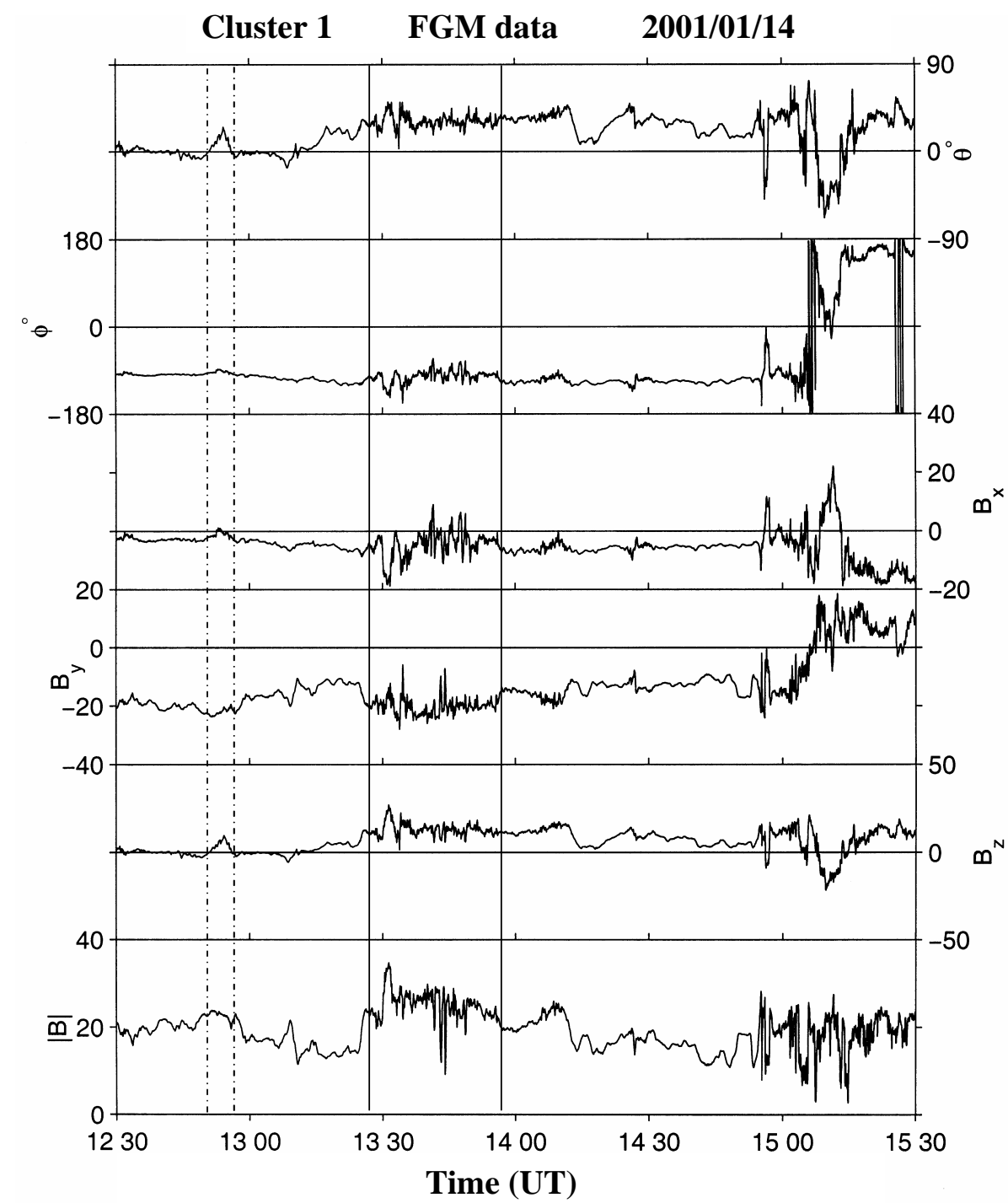

Fig. 4. Cluster magnetic field measurements versus time. The six panels from top to bottom show: the elevation angle $\theta$ (positive northwards), the longitude angle $\Phi$ (zero along the $X$-axis towards the Sun, and positive duskwards), the GSE components $B_{X}, B_{Y}, B_{Z}$ and the total magnetic field. The two vertical dot-dashed lines mark the first boundary layer encounter (BL-E1), and the two vertical full lines mark the second boundary layer encounter (BL-E2). spin plane, it is possible to calculate $E_{Z}$ from the assumption that $E_{\|}>E_{\perp}$ and $\boldsymbol{E} \cdot \boldsymbol{B} \cong 0$, which will be seen in Sect. 4.2. Figure 4 shows the corresponding magnetic field observations for the interval of 12:30-15:30 UT. Plotted in the panels from top to bottom are: the elevation angle $\theta$ (angle made by the magnetic field vector with the $X-Y$-plane, positive northwards), the longitude angle $\Phi$ (zero along the $X$-axis towards the Sun and positive duskwards), the GSE components $B_{X}, B_{Y}, B_{Z}$, and the total magnetic field. The pair of vertical dashed lines and the pair of vertical full lines mark the duration that the boundary layer encounters, BL-E1 and BL-E2, respectively. It is notable from Fig. 4 that the ambient magnetic field of Cluster is dominated by a negative $B_{Y}$ component up to about $13: 15$, i.e. a duskward directed field. $B_{Z}$ experienced a positive deflection associated with BL-E1, while $B_{Y}$ stayed around $-20 \mathrm{nT}$ and $B_{X}$ was nearly zero. The fluctuation level is apparently much higher during BL-E2 than during BL-E1. The irregular pulsations are observed during BL-E2 and after 14:55 UT, when the space- craft definitely traversed the magnetopause and entered the magnetosheath.

Figure 5 presents a sequence of $630.0 \mathrm{~nm}$ all-sky images from $\sim 12: 44$ to $12: 56 \mathrm{UT}$. The raw images have been cut at a $75^{\circ}$ zenith angle and projected onto a map, assuming an altitude of $250 \mathrm{~km}$ for the $630.0 \mathrm{~nm}$ emission. The acquisition time is given at the top of each frame. The first image was taken at 12:44 UT when DMSP-14 (ground-track is given by the red line) intersected structured auroral activity near the east coast of Greenland. The rest of the sequence covers the time interval when Cluster encountered BL-E1. The Cluster ground-track was calculated by the T96 model which required IMF $B_{X}, B_{Y}$ and $B_{Z}$, the solar wind dynamic pressure, and the magnetic Dst index as input. For all the mappings in this paper, we used constant values for the solar wind pressure and the Dst index. For the solar wind pressure, we used $0.5 \mathrm{nPa}$, which is an average value for the actual time interval. The hourly average of the Dst was -2 nT. For IMF, we have experimented with 60 and 

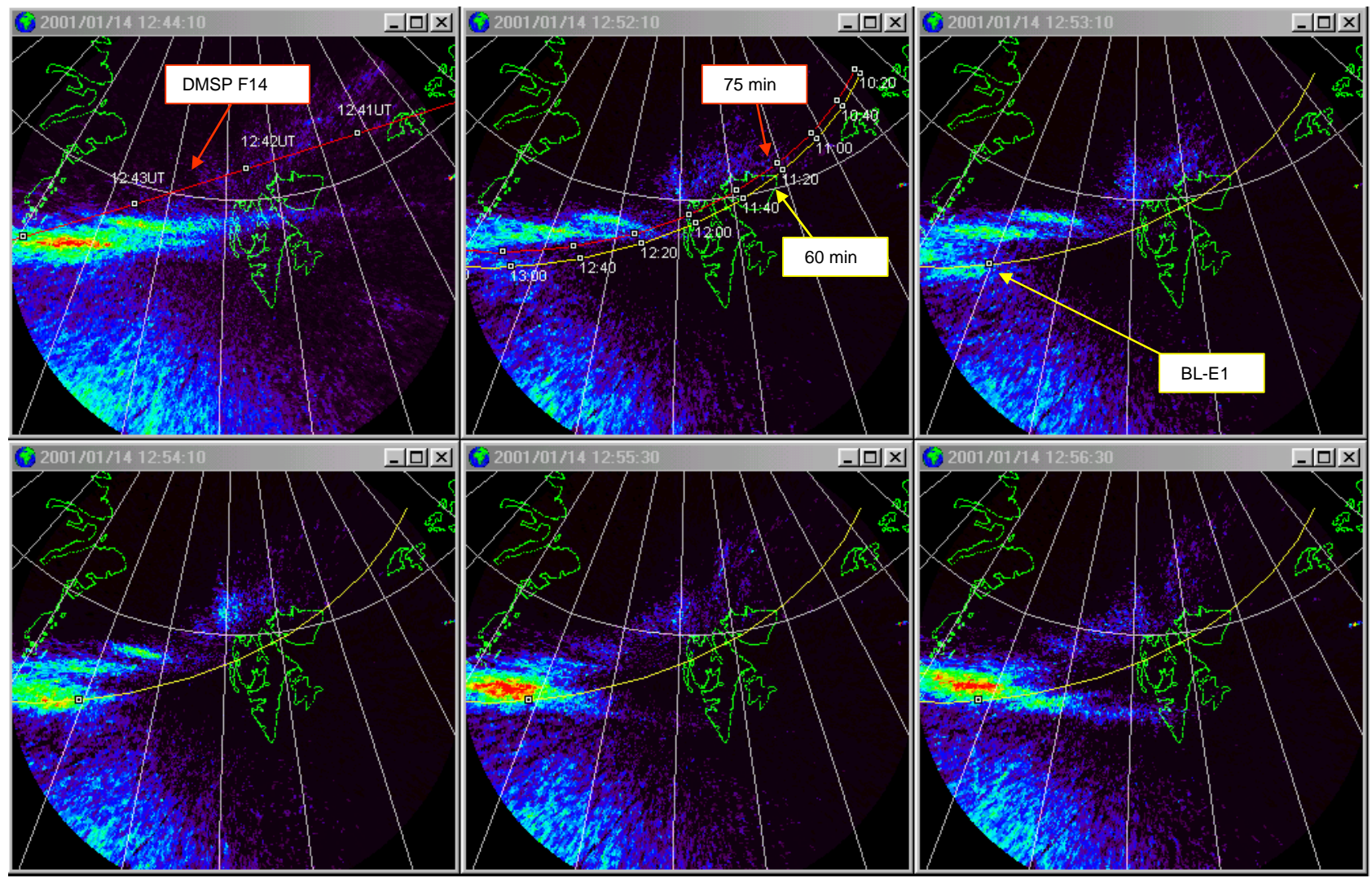

Fig. 5. A sequence of digital all-sky images of the $630.0 \mathrm{~nm}$ emission taken at Ny-Ålesund displayed on a geographical frame of reference. The auroral emission is mapped to an Earth-centred sphere at $250 \mathrm{~km}$. Time is given at the top of each frame. The colour scale is linear with increasing intensity from blue to red. The red straight line intersecting the auroral activity near the east coast of Greenland in the 12:44:10 UT image marks the trajectory of a DMSP-F14 pass. The red and the yellow curves in the following image represent the nominal ground tracks of Cluster calculated for two different time lags of the IMF observations, 75 and $60 \mathrm{~min}$, respectively.

75 min time lags for the IMF. The yellow curved line superimposed on the frames from 12:52 UT onwards in Fig. 5 represents a $60 \mathrm{~min}$ time lag, i.e. IMF values: $B_{X}=-4.2 \mathrm{nT}$, $B_{Y}=-2.0 \mathrm{nT}, B_{Z}=0 \mathrm{nT}$. The red curve north of the yellow one in the 12:52 UT frame demonstrates a 75 min time lag and IMF values: $B_{X}=-4.6 \mathrm{nT}, B_{Y}=0 \mathrm{nT}, B_{Z}=2 \mathrm{nT}$. Cluster's position along the ground-track is marked with a white square at $20 \mathrm{~min}$ intervals in the top middle frame from 10:20 UT until it went out of the field-of-view over Greenland around 13:20 UT. In the subsequent frames, the calculated position corresponding to the time the picture was taken has been marked on the yellow curve $(60 \mathrm{~min}$ time lag). It should be kept in mind that static magnetic field mapping can only give us a proxy of the ionospheric foot track since it does not account for dynamic movements of the magnetopause and the boundary layers. However, in the 11:52 UT image, we see two arc filaments between Greenland and Svalbard, located poleward of the nominal Cluster path (both paths). At $\sim 12: 53 \mathrm{UT}$, a third form brightened near eastern Greenland. This form intruded in the field-of-view in a region equatorward of where the other two subsequently faded, between 12:54:10 and 12:55:30 UT. This third form reached the Cluster footprint between 12:52 and 12:53 UT. The auro- ral form expanded further eastward, and retreated poleward from 12:55 UT. At 12:56:30 UT, the footprint of Cluster was at the equatorward edge of the auroral transient. Please note that enter and exit times of Cluster into BL-E1 corresponds in time with the auroral form moving over the satellite groundtrack.

Figure 6 shows electron and ion particle fluxes and plasma flow measured by DMSP-F14 along the track illustrated in the top left frame of Fig. 5. The satellite flew southwest closely adjacent to the discrete $630.0 \mathrm{~nm}$ auroral activity from 12:43 UT onwards, and intersected a bright form around 12:44 UT, just before it left the camera's field-ofview. From 12:43 to 14:44:45 UT, the particle fluxes are dominated by low energy magnetosheath-like electron and ion fluxes, with a modest flux of energetic ions. The vertical (green curve) and horizontal (magenta curve) components of the cross-track plasma velocity are plotted in the bottom panel. Please note that the $630.0 \mathrm{~nm}$ activity is located on a sunward plasma flow.

Figure 7 shows a sequence of all-sky images demonstrating the auroral activity to be discussed in relation to Cluster's boundary layer excursion BL-E2 from 13:27-13:57 UT. The yellow ground-track was obtained assuming a $60 \mathrm{~min}$ time 


\section{F14 14 Jan 2001}

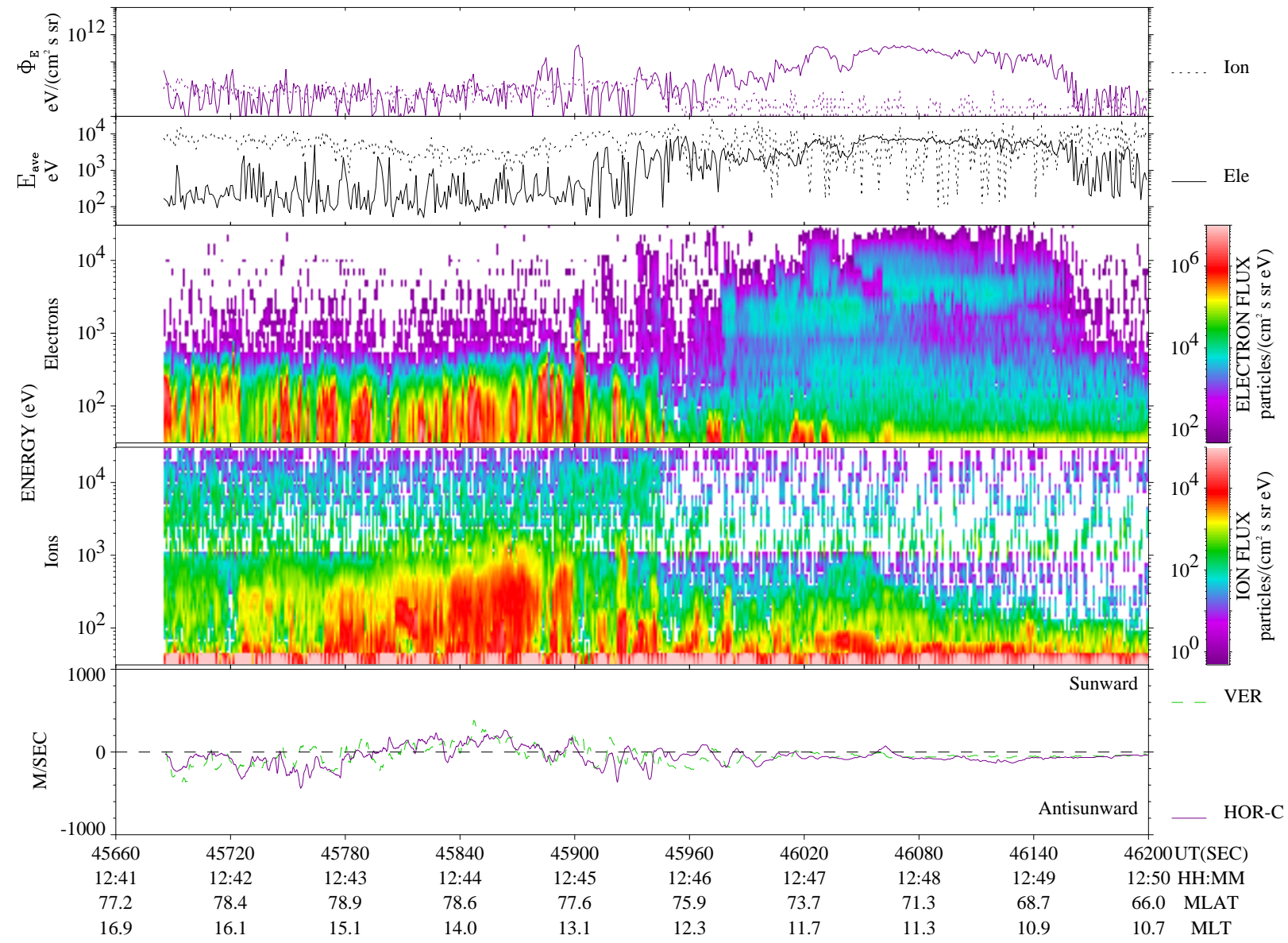

Fig. 6. DMSP-F14 observations of particle precipitation and plasma flow along the path indicated by the straight red line in the top left frame of Fig. 5. The upper two panels display energy flux and average energy for the ion and electron precipitation. The third and the fourth panels show electron and ion fluxes versus energy and time. The bottom panel displays the cross-track plasma flow versus time. The green curve represents the vertical component (positive upward) and the magenta curve represents the horizontal component (positive sunward).

lag for the IMF observations $\left(B_{X}=-3 \mathrm{nT}, B_{Y}=4 \mathrm{nT}\right.$, $B_{Z}=0 \mathrm{nT}$ ) and the red ground-track was obtained for a $75 \mathrm{~min}$ time lag $\left(B_{X}=-2.6 \mathrm{nT}, B_{Y}=-1 \mathrm{nT}, B_{Z}=4 \mathrm{nT}\right)$. The difference between the two will be discussed in Sect. 4 . At the event onset, Cluster had already moved out of the field-of-view over Greenland. We see an initial brightening above eastern Greenland around 13:31 UT. This activity expanded rapidly toward Svalbard. Between 13:41:30 and 13:44:10 UT, an auroral form detached from the main activity region and propagated east towards Heiss Island. NOAA-12 traversed the quasi-persistent auroral arc between 13:48 and 13:49 UT, as illustrated in the two right-hand frames in the bottom row of Fig. 7. The satellite flew along the straight red line from southeast to northwest. Electron particle data sampled along this trajectory are presented in Fig. 8. The solid curves in the three upper panels represent precipitating electrons at given energies, while the dot-dashed curves in the second and third panels represent fluxes perpendicular to the magnetic field. NOAA-12 crossed northbound through the $30 \mathrm{keV}$ electron-trapping boundary at 13:47:45 UT, indicated by the vertical line. North of the electron-trapping boundary, there is a belt of structured $0.3-0.46 \mathrm{keV}$ electron precipitation. At $\sim 13: 48: 30 \mathrm{UT}$, the electron energy flux peaked at $10 \mathrm{mWm}^{-2}$, which corresponds to the intersection of the bright arc. The characteristic energy associated with this distinct peak in energy flux is $1.4 \mathrm{keV}$. The eastward-moving form break off from the quasi-persistent background arc, as described above, was followed by two similar ones that tore off the background arc at $\sim 13: 51$ and $\sim 13: 53$ UT. Then the auroral activity ceased, and the background arc faded at the time Cluster went out of BL-E2 at 13:57 UT.

\section{Discussion}

The discussion section is organised as follows. First, we discuss the problems associated with field-aligned mapping. Then we focus on boundary layer sources and dynamics, and the associated auroral response. Finally, we will consider the 15:00-17:00 MLT cusp auroral activity in more detail. 

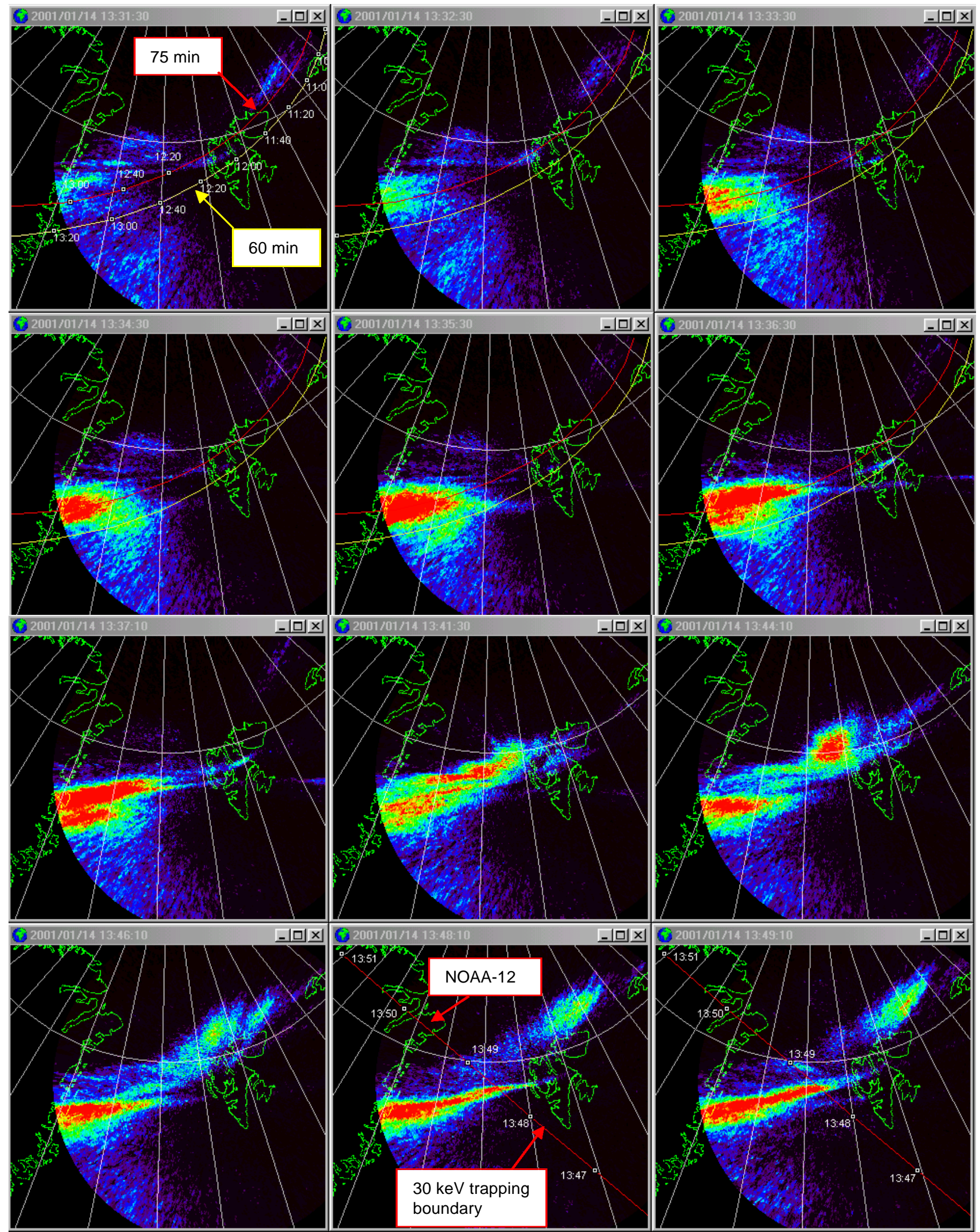

Fig. 7. An all-sky sequence for Cluster event BL-E2 presented in the same format as Fig. 5. The straight red line west of Svalbard in the 13:48:10 and 13:49:10 UT frames (bottom row) depicts the flight path of NOAA-12. 


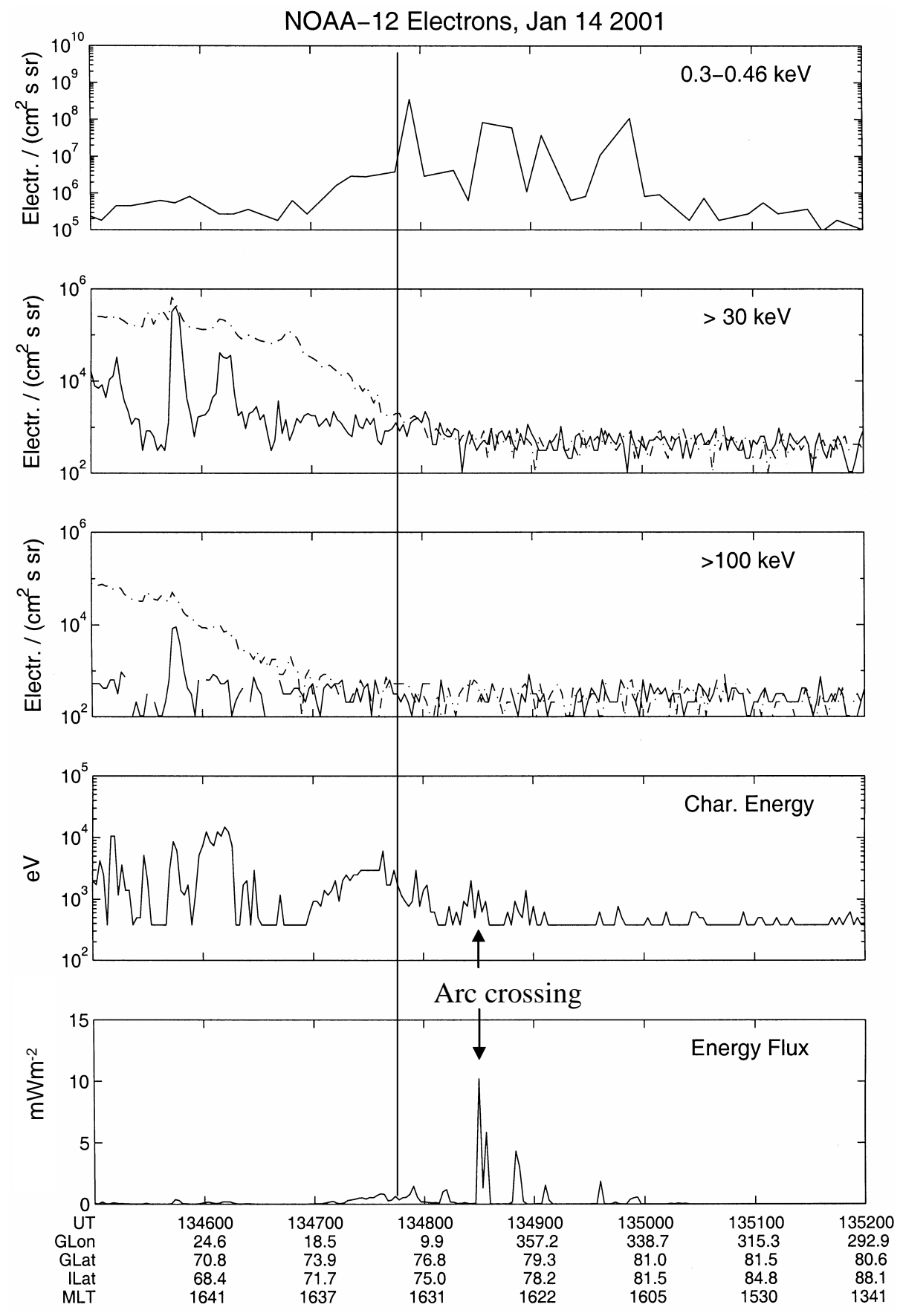

Fig. 8. NOAA-12 electron particle observations along the path indicated by the straight red line west of Svalbard in the 13:48:10 and 13:49:10 UT frames in Fig. 4 (bottom row). The upper panel shows the integral of downward moving electrons over the energy range 0.30 $0.46 \mathrm{keV}$. The second and third panels from the top represent the integral flux over $30-1000 \mathrm{keV}$ and $100-1000 \mathrm{keV}$ for electrons. The solid line is the flux measured along the zenith direction, and the dot-dashed line is the flux perpendicular to the zenith. The two bottom panels give characteristic energy and energy flux for the electron precipitation.
4.1 Field-aligned mapping and magnetic conjugate measurements

Mapping along magnetic field lines from the outer magnetosphere to the ground is a non-trivial task involving uncertainties. Since we do not know the exact time lag of the IMF observations we have used for each case two sets of driving parameters. Figure 8 illustrates a $\sim 80 \mathrm{~km}$ southeast shift of the ground trajectory, basically changing $B_{Y}=1 \mathrm{nT}$ to $4 \mathrm{nT}$ and $B_{Z}$ from $4 \mathrm{nT}$ to $0 \mathrm{nT}$. Ober et al. (2000) demonstrated a similar displacement for a polar pass over Svalbard. In order to obtain a quantitative agreement between electron fluxes observed by polar and the resulting auroral emissions in the ionosphere, they shifted the footprint trajectory by adjusting the dynamic pressure input to the model, i.e. they used dynamic pressure as a free parameter to obtain good correspondence between electron precipitation fluxes and auroral activity. For the two situations presented here, when the aurora is far off zenith of the optical site, a quantitative comparison between variations in auroral intensity and spectral content, with variations in field-aligned electron fluxes and energy, is not feasible. 
Despite all the uncertainties involved, the mapping in Fig. 3 ties the boundary layer crossing BL-E1 quite convincingly to the crossing of the discrete post-noon auroral form. It is not possible to judge the accuracy of the mapping in Fig. 4, as the Cluster footprint was west of the all-sky fieldof-view. However, the transient eastward expansion of the auroral activity coincided in time with Cluster's encounter of BL-E2, which indicates a close relationship between the two phenomena.

\subsection{Boundary layer crossings and plasma sources}

We conclude from Fig. 3 that Cluster was initially in the magnetosphere at 12:30 UT and had definitely crossed the magnetopause by 15:15 UT. In between these two extremes, Cluster had several encounters with a boundary layer populated by a magnetosheath plasma component, but not with quite as high densities as in the magnetosheath itself. During the first encounter, from 12:52-12:56 UT, the characteristic energy ranged from 50 to $60 \mathrm{eV}$, which is expected for the magnetosheath electron plasma. The density varied between $3-6 \mathrm{~cm}^{-3}$, which is an order of magnitude higher than in the magnetosphere, but significantly lower than in the magnetosheath.

The elevation angle of the magnetic field $(\theta)$ is small up to about 13:15 UT, which makes it impossible to calculate $\boldsymbol{E} \times$ $\boldsymbol{B} / B^{2}$ for the first event. However, the positive $E_{X}$ signature of $\sim 1 \mathrm{mV} / \mathrm{m}$ at the start and about $-1 \mathrm{mV} / \mathrm{m}$ at the end of BL-E1 can be combined with a corresponding $B_{Y}$ of $\sim 20 \mathrm{nT}$ to yield the $Z$-component of $\boldsymbol{E} \times \boldsymbol{B} / B^{2}$. At the beginning and the end, $\left(\boldsymbol{E} \times \boldsymbol{B} / B^{2}\right)_{Z}$ are, respectively, of the order of $-50 \mathrm{~km} / \mathrm{s}$ and $+50 \mathrm{~km} / \mathrm{s}$, indicating an inward motion at the beginning and an outward motion at the end.

The spacecraft potential is a key parameter for accurately defining boundary layer crossings. The time sequence of spacecraft potential changes, combined with the separation between the spacecraft, can be used to identify the approximate boundary orientation and velocity. The spacecraft potential measurements have a time resolution of $0.1 \mathrm{~s}$ and have been used for detailed studies of dusk flank magnetopause crossings (Bale et al., 2001). These authors found periodic bulges of the magnetopause, probably due to Kelvin-Helmholtz instabilities and boundary motions of typically 50$100 \mathrm{~km} / \mathrm{s}$. All boundary and magnetopause motions have velocities far greater than typical spacecraft velocities of a few $\mathrm{km} / \mathrm{s}$, and it is a good approximation to assume that the spacecraft are practically stationary. Figure 9 shows a high time resolution plot of the potential on all four spacecraft during the encounter of the BL-E1 structure. The spacecraft traverses the leading flank of the boundary layer, encountering it in the order of spacecraft 2, 3, 1 and 4. The same order is maintained when the spacecraft are leaving the boundary layer. This indicates that an inward bulge of the boundary layer propagated tailward over the satellites caused the inbound and outbound encounters. The increase in magnetic field strength associated with BL-E1 (Fig. 4) is indicative of a compressional MHD wave. For this case, the boundary sur- face was relatively close to the model magnetopause and at the encounter, it moved in the $-X$ and slightly in the $+Y$ directions with a velocity of $30-40 \mathrm{~km} / \mathrm{s}$. The return to the magnetopause is more irregular and difficult to analyse.

The auroral brightening south of the pre-existing activity, seen from 12:53 UT onwards in Fig. 5, seems consistent with the inward push of the boundary layer. The eastward motion/expansion of this form may correspond to the tailward movement of the boundary layer structure seen by Cluster. The auroral form attributed to BL-E1 was an intensification within the active band traversed by DMSP-F14 $\sim 10$ min earlier. DMSP-F14 probed a mixture of intense magnetosheathlike ion and electron fluxes with a small flux of energetic ions, which is a key characteristic of the LLBL. The auroral activity was found to be located on sunward convecting field lines. Under the prevailing north IMF $B_{Z}$, and without any signatures of energy dispersed ions, the LLBL aurora are likely to be located on closed field lines (Newell and Meng, 1998). Hence, it is reasonable to propose that Cluster had a brief encounter with a closed LLBL.

At 13:27 UT, spacecraft 1 made another crossing out of the magnetosphere, again marked by the disappearance of highenergy electrons and the occurrence of a colder and denser population. This population is characterised by energies in the range of $50-80 \mathrm{eV}$ and densities of $20-40 \mathrm{~cm}^{-3}$. Note that in a short interval between 13:30 and 13:32 UT, $N_{e}$ increases to magnetosheath values (marked MSh in Fig. 3). $B_{Z}$ increased to $20 \mathrm{nT}$, and the $\boldsymbol{E} \times \boldsymbol{B}$ velocity increased to $125 \mathrm{~km} / \mathrm{s}$ in the $-X$ and $+Y$ directions, which is the expected direction and velocity in the magnetosheath. Therefore, this was a clear crossing of the magnetopause. The spacecraft returned to a less dense plasma, presumably just inside the magnetopause, and the satellite remained in this environment until 13:57 UT when it again returned into the magnetosphere, as seen by the reappearance of the high-energy electrons. It is interesting to observe that for the brief MSh interval of 13:30 to 13:32 UT, electron energy was nearly identical to that observed deeper in the magnetosheath at 15:10 UT. In the interval of 13:40-13:43 UT (inside the magnetopause), the electron energy was higher (increase from a $25-75 \mathrm{eV}$ range to a $35-120 \mathrm{eV}$ range). This period very likely represented a crossing of the outer cusp region (around $13 R_{E}$ ). It turned out to consist of a fairly structured electron population with irregular density variations, but a general increase towards higher energies during the crossing.

Opgenoorth et al. (2001, this issue) have synthesised a global picture of the cusp reconfiguration associated with BL-E2. In a detailed analysis, they demonstrate how the cusp moved from an initially pre-noon location into the late postnoon sector. The eastward expansion over Svalbard is nicely illustrated in Fig. 7. Moen et al. (1999) reported a rapid eastward shift of at least 3 hours in magnetic local time controlled by a transition in the IMF $B_{Y}$ from -15 to $+15 \mathrm{nT}$. Sandholt et al. (1999) reported a similar transient expansion of the cusp aurora into the post-noon sector in response to a sharp southward turning of the IMF. In the case presented here, the reconfiguration of the cusp was likely controlled by 


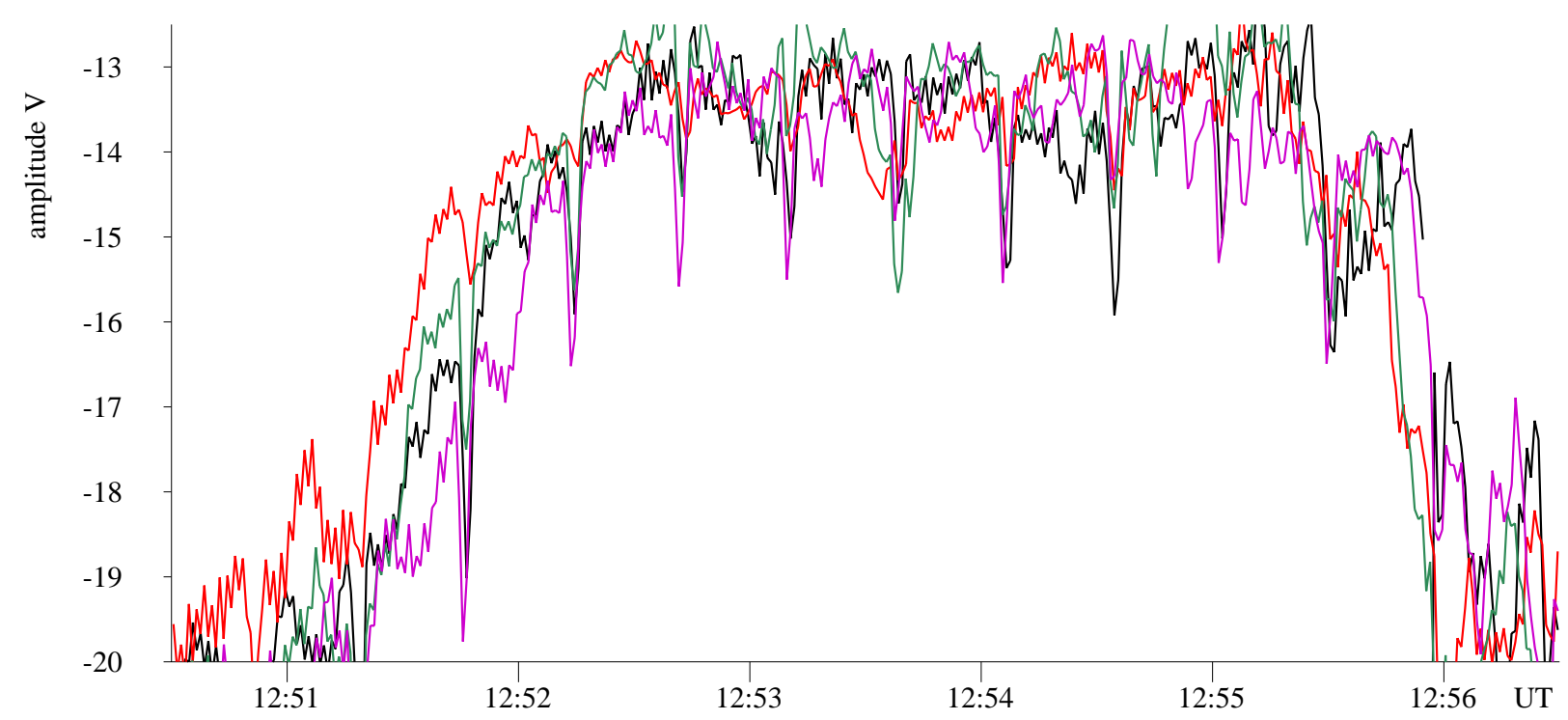

Fig. 9. High time resolution plots of the negative of the spacecraft potential of the four Cluster spacecraft during the BL-E1 encounter. The data points represent $1 \mathrm{~s}$ averages. The scale of the potential of spacecraft 2 has been adjusted to be on the same level as the other three. Due to an unscheduled high beam current in the EDI experiment, this spacecraft was shifted to a lower potential. The periodic dips in the potential are due to the operation of the Whisper sounder.

the combination of a positive gradient in $B_{Y}$ and the negative gradient in $B_{Z}$, observed at the ACE location between $\sim$ 12:15 and 12:45 UT. The Pi-1 pulsations observed during BL-E2 (but not during BL-E2) is an indication of open field lines and turbulent plasma. We recall from Sect. 3 that the auroral activity ceased and the background arc faded at the time Cluster left BL-E2. Therefore, it is likely that Cluster's encounter with BL-E2 was facilitated by an eastward expansion of the cusp over the spacecraft, and that it retreated to the magnetosphere when the extraordinary strong cusp event ceased.

\subsection{Cusp auroral activities in the late post-noon sector}

NOAA-12 cut through the east end of the auroral activity that surged into the field-of-view from the west and reached Svalbard around 13:41 UT (see Fig. 4). It passed the $30 \mathrm{keV}$ electron-trapping boundary marked by the vertical line in Fig. 5 at 13:47:45 UT. By inspecting the red satellite path in the 13:48:10 UT frame of Fig. 4, we can see that the satellite was then at a position well south of the bright $\operatorname{arc}(\sim 250 \mathrm{~km})$. Sometimes a drizzle of energetic electrons occurs south of the electron-trapping boundary, giving rise to a $557.7 \mathrm{~nm}$ glow aurora (Moen et al., 1998), termed a type 3 aurora by Sandholt et al. (1998) (see Introduction). A type 3 aurora was not observed here, but we can see some precipitating highenergy electrons around 13:46 UT (the solid curve in the sec- ond and third panels in Fig. 5). Poleward of the electrontrapping boundary, a significant flux of $0.3-0.46 \mathrm{keV}$ electrons was observed between 13:47:45-13:50 UT, likely of magnetosheath origin, and it gave rise to the faint $630.0 \mathrm{~nm}$ luminosity seen at either side of the bright arc. The most significant energy flux peaking at $10 \mathrm{mWm}^{-2}$, corresponding to the bright arc, was not spectrally resolved by NOAA- 12 . However, the characteristic energy of $1-2 \mathrm{keV}$ indicates that the precipitating electrons had been through a potential drop, and that the arc is representing an upward field-aligned current sheet. In light of accumulated knowledge from DMSP observations, the region of structured electron precipitation and inverted Vs, mixed with a low energy component in this time sector (16:30 MLT), is what traditionally is classified as a BPS precipitation (see Introduction).

Another very interesting feature of the auroral activity observed in Fig. 7 is the sequence of moving auroral forms detaching from the quasi-persistent background arc. At $\sim$ 13:42 UT, the first form in the sequence separated from the background aurora between Greenland and Svalbard and subsequently drifted eastward. This moving auroral form was followed by two similar ones that separated from the active region at $\sim 13: 51$ and $\sim$ 13:53 UT, after which all the activity faded. The category of moving auroral forms is taken as a candidate signature of flux transfer events (FTEs; e.g. Sandholt et al., 1993 and Moen et al., 1995). This is probably 
the type of auroral activity that Sandholt et al. (1998) named type 7 (see Introduction), which they pointed out is similar to the type 1 activity, except for the more intense $557.7 \mathrm{~nm}$ emission. Milan et al. (2000) attributed a discrete Polar UVI arc extending into the 19:00 MLT sector to a reconnection $X$-line. Poleward-moving forms emanated from this arc in the 14:00-16:00 MLT sector, very similar to what we have reported here.

\section{Summary and concluding remarks}

We have related two boundary layer encounters experienced by Cluster to dynamic changes in the 15:00-17:00 MLT auroral activity observed between Greenland and Svalbard. We have demonstrated the use of the T96 model to identify the nominal Cluster footprint in the ionosphere. Although the mapping is quite sensitive to solar wind conditions, it appears to be a strong tool to identify the ionospheric regions of interest. The first boundary layer encounter occurred when the cusp was located in the pre-noon sector (Opgenoorth et al., this issue), and was addressed to closed LLBL field lines on a sunward convecting flow. The observations were found to be consistent with an inward bulge propagating tailward, most likely a boundary layer wave. The other boundary layer encounter was found to be consistent with a rapid reconfiguration of the cusp, which moved over the spacecraft into the post-noon sector. The IMF was dominated by a negative $B_{X}$ component and an increasingly positive $B_{Y}$ which is in favour of dusk flank reconnection. Therefore, it is quite unlikely that Cluster was close to a merging location in this case. A more detailed study including all electron and ion particle data with pitch-angle information will be conducted in order to identify key signatures to discriminate between open and closed dayside boundary layers. Finally, this study supports the view that cusp auroral activity may occur in the very late post-noon sector, and that discrete auroral forms and accelerated electron beams may occur on open field lines.

Acknowledgements. The Norwegian Research Council has funded the Norwegian participation in the Cluster mission. This work has also benefited from the AFOSR grant F61775-01-WE014. We wish to acknowledge the World Data Centre for Geomagnetism for providing the Dst magnetic index, and to California Institute of Technology for giving www-access to ACE satellite data. A special thank to D. Evans for providing NOAA particle data. Thanks to K. Stasiewicz and co-workers who have developed the orbit visualisation tool for Cluster.

Topical Editor M. Lester thanks S. W. H. Cowley and another referee for their help in evaluating this paper.

\section{References}

Bale, S. D., Mozer, F. S., Andre, M., Ericsson, A., Gustaffson, G., Holmgren, G., Lindqvist, P.-A., Holtet, J. A., Lybekk, B., Pedersen, A., Grard, R., Laakso, H., Mursula, K., Tanskanen, P., and Yerby, K.: The normal, thickness, and speed of the dusk magnetopause from Cluster electric field and wave experiment measurements, submitted to Geophys. Res. Lett., 2001.

Balogh, A., Dunlop, M. W., Cowley, S. W. H., Southwood, D. J., Thomlinson, J. G., Glassmeier, K. H., Musmann, G., Lühr, H., Buchert, S., Acuña, M. H., Fairfield, D. H., Slavin, J. A., Riedler, W., Schwingenschuh, K., Kievelson, M. G., and the Cluster magnetometer team: The Cluster Magnetic Field Investigation, in The Cluster and Phoenix missions, (Eds) Escoubet, C. P., et al., Kluwer Academic Press, Dordrecht, 65-92, 1997.

Farrugia, C. J., Sandholt, P. E., Maynard, N. C., Burke, W. J., Scudder, J. D., Ober, D. M., Moen, J., and Russell, C. T.: Pulsating mid-morning auroral arcs, filamentation of a mixing region in a flank boundary layer, and ULF ULF waves observed during a POLAR-Svalbard conjunction, J. Geophys. Res., 105, 27531 27 554, 2000.

Gustafsson, G., André, M., Eriksson, A.I., et al.: First results of electric field and density observations by Cluster EFW based on initial amounts of operations, Ann. Geophysicae, this issue, 2001.

Johnstone, A. D., Alsop, C., Burge, S., Carter, P. J., Coates, A. J., Coker, A. J., Fazakerley, A. N., Grande, M., Gowen, R. A., Gurgiolo, C., Hancock, B. K., Narheim, B., Preece, A., Sheather, P. H., Winningham, J. D., and Woodliffe, R. D.: PEACE: A plasma electron and current instrument, Space Sci Rev, 79, 351398, 1897. Reprinted in (Eds) Escoubet, C. P., Russell, C. T. and Schmidt, R. The Cluster and Phoenix missions, Kluwer Academic Press, Dordrecht, 1997.

Lockwood, M.: Identifying the open-closed field line boundary, in Polar Cap Boundary Phenomena, (Eds) Moen, J., et al., Advanced Study Institute Series, Kluwer Academic Press, Dordrecht, Vol. 509, 415-432, 1998.

Lockwood, M. and Moen, J.: Ion populations on open field lines within the low-latitude boundary layer: theory and observations during a dayside transient event, Geophys. Res. Lett., 23, 28952898, 1996.

Lockwood., M., Fuselier, S., Walker, A. D. M., and Søraas, F.: A summary of the NATO ASI on polar cap boundary phenomena, in Polar Cap Boundary Phenomena (Eds) Moen, J., et al., NATO Advanced Study Institute Series, Kluwer Academic Press, Dordrecht, Vol. 509, 415-432, 1998.

Lockwood, M., Opgenoorth, H., van Eyken, A. P., Fazakerley, A., Bosqued, J. M., Denig, W. F., Wild, J., Cully, C., Greenwald, R., Lu, G., Amm, O., Frey, H., Strømme, A., Prikryl, P., Hapgood, H. A., Wild, M. N., Stamper, R., Taylor, M., McCrea, I., Kauristie, K., Pulkinnen, T., Pitout, F., Balogh, A., Dunlop, M., Rème, H., Behlke, R., Hansen, T., Provan, G., Eglitis, P., Morley, S. K., Alcaydé, D., Blelly, P.-L., Moen, J., Donovan, E., Engebregtson, M., Lester, M., Waterman, J., and Marcucci, M. F.: Coordinated Cluster, ground-based instrumentation and low-altitude satellite observations of transient poleward moving events in the ionosphere and the tail lobe, Ann. Geophysicae, this issue, 2001.

Lorentzen, D. A., Deehr, C. S., Minow, J. I., Smith, R. W., Stenbaek-Nielsen, H. C., Sigernes, F., Arnoldy, R. L., and Lynch, K.: SCIFER-Dayside auroral signatures of magnetospheric energetic electrons, Geophys. Res. Lett., 23, 1885-1888, 1996.

Lorentzen, D. A. and Moen, J.: Auroral proton and electron signatures in the dayside aurora, J. Geophys. Res., 105, 12733 $12745,2000$.

Milan, S. E., Lester, M., Cowley, S. W. H., and Brittnacher, M.: Convection and auroral response to a southward turning of the IMF: Polar UVI, CUTLASS, and IMAGE signatures of transient 
magnetic flux transfer at the magnetopause, J. Geophys. Res., 105, 15 741-15 755, 2000.

Moen, J., Sandholt, P. E., Lockwood, M., Denig, W. F., Løvhaug, U. P., Lybekk, B., Egeland, A., Opsvik, D., and Friis-Christensen, E.: Events of enhanced convection and related dayside auroral activity, J. Geophys. Res., 100, 23 917-23 934, 1995.

Moen, J., Evans, D., Carlson, H. C., and Lockwood, M.: Dayside moving auroral transients related to LLBL dynamics, Geophys. Res. Lett., 23, 3247-3250, 1996.

Moen, J., Lorentzen, D. A., and Sigernes, F.: Dayside moving auroral forms and bursty proton auroral events in relation to particle boundaries observed by NOAA-12, J. Geophys. Res., 103, 14 855-14 863, 1998.

Moen, J., Carlson, H. C., and Sandholt, P. E.: Continuous observations of cusp auroral dynamics in response to an IMF $B_{Y}$ polarity change, Geophys. Res. Lett., 26, 1243-1246, 1999.

Newell, P. T. and Meng, C.-I.: The cusp and the cleft/boundary layer: low-altitude identification and statistical local time variation, J. Geophys. Res., 93, 14 549-14 556, 1988.

Newell, P. T. and Meng, C.-I.: Mapping the dayside ionosphere to the magnetosphere according to particle precipitation characteristics, Geophys. Res. Lett., 19, 609-612, 1992.

Newell, P. T. and Meng, C.-I.: Open and closed low latitude boundary layer, in Polar Cap Boundary Phenomena, (Eds) Moen, J., et al., NATO Advanced Study Institute Series, Kluwer Academic Press, Dordrecht, 509, 91-101, 1998.

Ober, D. M., Maynard, N. C., Burke, W. J., Moen, J., Egeland, A., Sandholt, P. E., Farrugia, C. J., Weber, E. J., and Scudder, J. D.: Mapping of ionospheric auroral features associated with the prenoon boundary layer to the magnetosphere, J. Geophys. Res., 105, 27 519-27 530, 2000.

Øieroset, M., Sandholt, P. E., Denig, W. F., and Cowley, S. W. H.: Northward interplanetary magnetic field cusp aurora and high-latitude magnetopause reconnection, J. Geophys. Res., 102, 11349-11362, 1997.

Opgenoorth, H, Lockwood, M., Alcaydé, D., Donovan, E., Engebretson, M. J., van Eyken, A. P., Kauristie, K., Lester, M., Moen, J., Waterman, J., Alleyne, H., André, M., Dunlop, M. W., Cornilleau-Wehrlin, N., Décréau, P. M. E., Fazerkerley, A., Rème, H. M., André, R., Amm, O., Balogh, A., Behlke, R., Blelly, P. L., Boholm, H., Borälv, E., Bosqued, J. M., Buchert, S., Candidi, M., Cerisier, J. C., Cully, Ch., Denig, W. F., Doe, R., Eglitis, P., Greenwald, R. A., Jackal, B., Kelly, J. D., Krauklis, I., Lu, G., Mann, I. R., Marcucci, M. F., McCrea, I. W., Maksimovic, M., Massetti, S., Masson, A., Milling, D. K., Orsini, S., Pitout, F., Provan, G., Ruohoniemi, J. M., Samson, J. C., Schott, J. J., Sedgemore-Schulthess, F., Stamper, R., Stauning, P., Strømme, A., Taylor, M., Vaivads, A., Villain, J. P., Voronkov, I., Wild, J., and Wild, M.: Coordinated ground-based, low altitude satellite and Cluster observations on global and local scales during a transient postnoon sector excursion of the magnetospheric cusp, Ann. Geophysicae, this issue, 2001.

Sandholt, P. E., Moen, J., Rudland, A., Opsvik, D., Denig, W. F., and Hansen, T.: Auroral event sequences at the dayside polar cap boundary for positive and negative IMF $B_{Y}$, J. Geophys. Res., 98, 7737-7755, 1993.

Sandholt, P. E., Farrugia, C. J., Moen, J., Noraberg, Ø., Lybekk, B., Sten, T., and Hansen, T. L.: A classification of dayside auroral forms and activities as a function of IMF orientation, J. Geophys. Res., 103, 23 325-23 345, 1998.

Sandholt, P. E., Farrugia, C. J., and Lybekk, B.: The dynamic cusp aurora on 30 November 1997: response to southward turning of the IMF, Ann. Geophysicae., 17, 1155-1165, 1999.

Tsyganenko, N. A.: Modelling the Earth's magnetospheric magnetic field confined with a realistic magnetopause, J. Geophys. Res., 100, 5999, 1995. 